progress of knowledge and the accumulation of experience.

One might dispute Jasanoff's assertion that there "was no storehouse of precedents that policymakers could reach into for historically documented evidence concerning the widespread use of laboratory-crafted organisms". Modern biotechnology brings precision, but no fundamental change, to the long-standing practices of selective breeding and random mutagenesis, which had been used in the fermentation and seed industries for many decades before the debates on recombinant DNA.

Jasanoff's thesis rests on stronger ground when she turns to the ethical impacts of modern biotechnology and genomics, and the differing national responses, which she discusses and compares in detail: "Genetic engineering transgresses some of the most deeply entrenched categories of western thought... Designs on nature - once thought to be the prerogative only of a divine creator - seem now well within the reach of human capability, she writes. The "controlling narratives" that framed the course of policy development include not only a novel process for intervening in nature, and a source of new products, but " a state-sponsored program of standardization and control carrying profound implications for human dignity and freedom, and raising questions of constitutional significance. . Given the profundity of the challenges thus brought into public and policy debates, democratic theory in the era of the knowledge society must take on board the involvement of citizens in the production, use and interpretation of knowledge for public purposes.

She offers three main conclusions. First, that core concepts of democracy such as citizenship and accountability cannot be satisfactorily understood without considering the politics of science and technology. Second, that in all three countries (and the EU), policies for the life sciences have been incorporated into 'nation-building' projects that seek to reimagine what the nation (or Europe) stands for. Third, that political culture matters to democratic culture, and works through the institutionalized ways in which citizens understand and evaluate public knowledge. These three aspects of contemporary politics help account not only for policy divergences between nations, but also for the perceived legitimacy of state actions.

These conclusions are well supported, and useful not least for indicating why scientific, industrial or other communities have found it difficult to influence policy. So the book succeeds in its aims. The policy debates have served to crystallize the emergence of a European polity and self-awareness. But the reader is left wondering: what if these high policy debates are founded on misperceptions, which they reinforce?

Mark Cantley is adviser, Research Directorate-

General of the European Commission, on

Biotechnology, Agriculture and Food.

\title{
A scientist's life in Russia
}

\section{About Science, Myself and Others \\ by V.L. Ginzburg, \\ Institute of Physics/Taylor \& Francis: 2004. \\ 549 pp. $\$ 99.95$}

\section{Alan L. Mackay}

Vitali Ginzburg, winner of the 2003 Nobel Prize for physics, was born in Moscow in 1916. He has survived, through intellect, character and chance, through the whole tempestuous and tragic period of the Soviet Union. He experienced two world wars, a revolution, leninism, stalinism, the fall of the Soviet Union, and the chaotic present-day reconstruction of Russia at the hands of 'gangster capitalism.'

About Science, Myself and Others deals with some immense topics: the circumstances of the Soviet Union, the history of branches of fundamental physics, and the lives of distinguished physicists, especially Lev Landau. In particular, Ginzburg focuses on struggles in three main areas: fundamental physics, the mechanics of daily life, and the ideologies of politics and religion.

Since the rise of Mikhail Gorbachevin 1985, Ginzburg has produced various accounts of his life and work, biographical sketches of his contemporaries, and more general pieces. About Science, Myself and Others is an English translation of the latest Russian edition, from 2003, which brought together scattered material but with some repetition and no index. It also contains material based on chapters published in his earlier book The Physics of $a$ Lifetime (Springer, 2001), and includes its contents list. The new collection contains a mass of detailed information on physics and on people, making it indispensable, particularly to those interested in the school of Landau and his fellow Nobel laureate Igor Tamm.

Ginzburg writes his apologia pro vita sua not as an apology but with a (justified) ${ }^{\alpha}$ fair conceit of himself" for posterity as his "version of the facts". He makes little concession to the ignorant and suggests a simple test of general knowledge for politicians and others. For example: "Q. What causes the seasons? A. The inclination of the axis of the Earth to the plane of its orbit." He writes that he has found interviews unsatisfactory, and in one paper he even wrote both the questions and his answers.

Most people have sought " to render unto Caesar what is Caesar's and to God what is God's", with a boundary between their inner beliefs and the society in which they live. But Ginzburg has always had an intense concern not just for physics but for the welfare of Russia. In 1989, during the Gorbachev era, he even became a deputy in the Supreme Soviet (the parliament), representing the Soviet Academy of Sciences, but left politics in 1991. In recent years he has been "an incorrigible

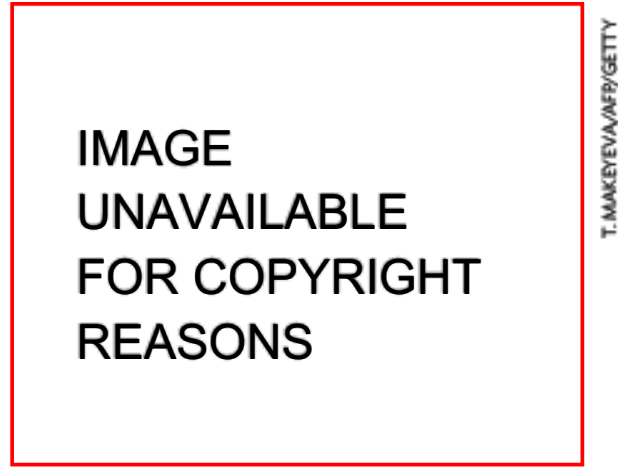

Vitali Ginzburg looks back on the science that flourished amid the political turbulence in Russia.

atheist", and campaigned against the revival of the Orthodox Church and pseudoscience of all kinds.

Ginzburg never suffered personal repression from the authorities, and in fact was honoured by the state, primarily for his work on the nuclear-weapons programme. He made a key contribution to the physics of the hydrogen bomb, proposing the use of lithium-6 deuteride as a nuclear source - a suggestion that surprised the Americans and brought him, in late 1953, the Order of Lenin and the Stalin prize first class. $\mathrm{He}$ might otherwise have suffered repression from the state following his marriage to Nina Ermakova, who had been exiled to Gorki and whose father was falsely regarded as an enemy of the state.

If history is a line with branch points at arbitrary decisions, then the whole manifold of all possible trajectories might be viewed as a tree. If this is the history of Russia, what shape is this tree of all possible paths? How different could it have been? The science theoretician Arnosht Kolman entitled his autobiography of disillusionment Our Lives Should Have Been Different (1982). How would Nikolai Bukharin, for example, have dealt with the situation if he, instead of Stalin, had succeeded Lenin?

Karl Marx hoped to discover laws and regularities in human history, as did the 'general systems' movement from Bertalanffy to Peter Turchin today, but the practical results have been slight. Ginzburg points to the key branch point: "I believe that the fundamental and principal cause of all these disasters is the Bolshevist-Communist totalitarian regime which was set up in Russia as a result of the coup détat in October 1917," which followed the February 1917 revolution that deposed the tsar.

The first part of the book is a detailed review of the physics that concerned Ginzburg, including radiation from uniformly moving sources (the Vavilov-Cherenkov effect), cosmic rays, soft modes, superconductivity and superfluidity. It manages to place his own 
work in a historical framework.

The second part of the book deals with history and includes biographical memoirs of several of his contemporaries, notably Landau, Tamm and Evgeni Lifshitz, but also Sergei Ivanovich Vavilov (brother of the geneticist Nikolai Vavilov and former president of the Soviet Academy of Sciences), as well as an autobiography. There is also an analysis of Russia's relationship with the Nobel prize, particularly in connection with C. V. Raman's prize for Raman scattering and the parallel work of G. S. Landsberg and L. I. Mandelstam, and with the discovery of the VavilovCherenkov effect. Finally, there is a collection of Ginzburg's publications on social and political questions, written with great factual detail and strong feeling.

In short, Ginzburg presents himself and his work, for the record, in the wider world of physics and of Russia.

Alan L. Mackay is in the School of Crystallography, Birkbeck College, University of London, Malet Street, London WCIE 7HX, UK.

\section{Families behaving badly}

\section{A Natural History of Families by Scott Forbes \\ Princeton University Press: 2005.248 pp. $\$ 27.95, £ 17.95$}

\section{Jonathan Wright}

I always feel that I am in a better position than many scientists when a friend or family member asks what my research is actually about. Compared with a theoretical physicist, it is relatively easy for me, as a behavioural ecologist, to enlighten and entertain members of the public, using the obvious parallels that exist between birds and humans in their family relationships. For example, there are disagreements between members of a pair over who does most of the childcare, and constant battles between overworked parents and their demanding offspring concerning apparently unimportant items of food. In his new book A Natural History of Families, Scott Forbes takes up this theme with a vengeance to reveal the many fascinating aspects of human family life and reproduction that arise from evolutionary conflicts of interest.

This 'popular' science book sells itself on the salacious revelation that all is not as nice as it seems within our cosy families and in the wonderful creation of an infant. As an avian biologist, the author presents a dispassionate account of parent-offspring conflict, siblicide and infanticide in animals and plants. But in the background lurks the disturbing fact that we are talking here about mothers and fathers, sons and daughters, and the family - an institution at the heart of human social experience.

The full horror is revealed when the author exposes at length the human side of the story. He describes research showing that 'morning sickness' and even pre-eclampsia (dangerously high blood pressure) during human pregnancy may be the manifestation of an evolutionary struggle between mother and child over placental blood flow and the frequent abortion of 'unfit' embryos. Fathers also get involved, and often on the side of the offspring. Certain genes become 'imprinted' only when inherited from the father, and these prompt the embryo to sequester even higher

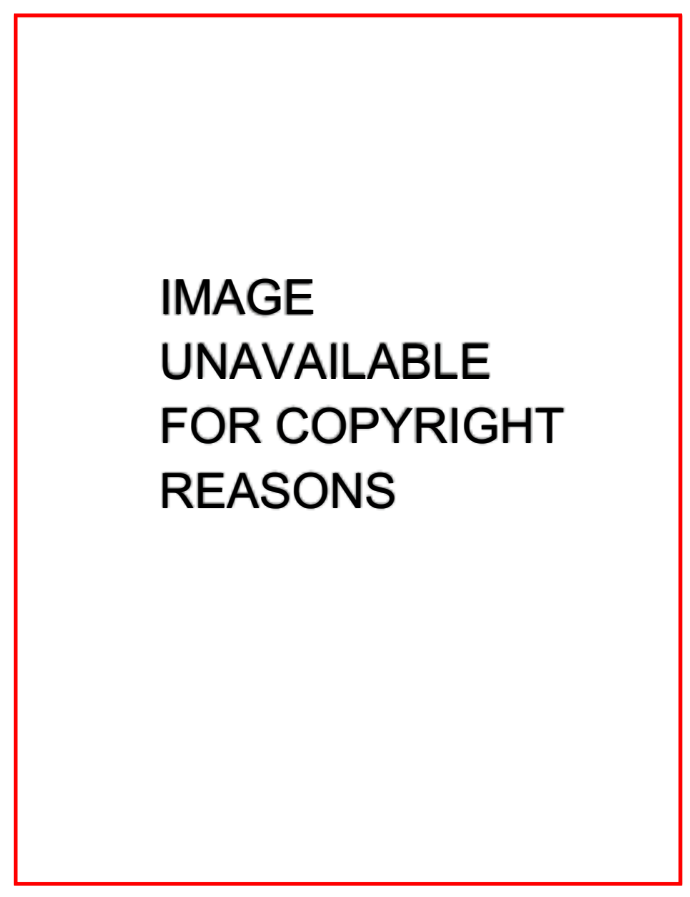

Who said we are meant to live in harmony? Makolm in the Middle sees the funny side of life in a dysfunctional family.

the ethical and philosophical implications of our own biology is not taken. Towards the end of the book, however, Forbes hints at a moral landscape. Somewhat negative language is used when describing current medical practices in assisted human reproduction. For example, the artificial implantation of multiple embryos increases the chance of a successful pregnancy, but inevitably it also increases multiple births of twins and triplets. This in turn creates its own problems (some as yet unknown) for the mother and especially for the future health and mental functioning of children born from artificial multiple pregnancies. The tragedy is that individual couples cannot afford the possibly healthier alternative of having fewer embryos implanted each time (because of the many more cycles that this would require), and most governments do not consider it their financial responsibility to step in, especially where older couples are concerned.

The analogy of Aldous Huxley's Brave New World is wheeled out to provide the usual warnings against the application of modern technology to human reproduction. Yet, evolutionarily speaking, Huxley's was perhaps a group-selectionist vision of excessive state control. The current 'customer-centred' health care that arises from free-market economics, and generates the social dilemma outlined above, might rather be described as an outcome of individual-level selection. But what, if any, should society's role be in moderating individual reproductive choices? I can't help feeling that the author, having implicitly introduced moral statements concerning modern human reproduction, bears some responsibility to discuss the ethical issues that follow from an evolutionary perspective if only to expose the complexity of the problem.

levels of resources from the mother.

Siblings are no better to one another, given the disturbing fact that some of us must have been murderers while in the womb: in more than $90 \%$ of human twin conceptions, mortality of one of the two embryos occurs. If we were a species of bird, this fact would classify us as an 'obligate brood reducer', along with those famously bloodthirsty little black eagle chicks.

How, then, do we react when we are told that these awful things are going on in our own families and inside our own bodies? More importantly, what do we think about the social and medical policies that perpetuate, or seek to modify, these phenomena? Does evolution provide a rationale for their continued existence, or a starting point for a better-informed programme of cultural and political change?

Unfortunately, the opportunity to explore
At the end of the day, this forayinto popular science perhaps does not do justice to the high quality of the author's own research on avian family conflict. In terms of outlining the underlying theory and non-human evidence, other texts, such as Douglas W. Mock's More Than Kin and Less Than Kind (Belknap Press, 2004), probably represent a better compromise between the popular and formal science formats. However, these do not attempt to deal explicitly with the tricky issues of human families and reproduction. In contrast, Forbes has taken on one of the hardest tasks in popularizing science, that of explaining to readers complex scientific findings about their own life and culture - and inevitably we all have our own opinions about that.

Jonathan Wright is in the Institute of Biology,

Norwegian University for Science and

Technology, Trondheim 7491, Norway. 